\title{
Citizen science in developing countries: how to improve volunteer participation
}

\author{
Fabrice Requier ${ }^{1,2,3^{*}}$, Georg KS Andersson ${ }^{1,2,4}$, Facundo J Oddi ${ }^{1,2}$, and Lucas A Garibaldi ${ }^{1,2}$
}

Citizen science is a powerful tool for connecting members of the public with research and for obtaining large amounts of data. However, it is far less commonly implemented in developing countries than in developed countries. We conducted a large-scale citizen-science program monitoring honey bee (Apis mellifera) colony losses in Argentina to examine how a national consortium composed of local coordinators and two different recruitment strategies influenced volunteer participation. These strategies consisted of online questionnaires and face-to-face interviews with beekeepers to record bee health issues. We found that use of both recruitment strategies was necessary because they reached different volunteer profiles and different locations, and therefore influenced the survey's results. Furthermore, public participation increased when the number of local coordinators was higher, regardless of recruitment strategy. These findings could also apply to other developing countries, where lack of internet access for some potential volunteers, logistical constraints such as long distances, and poor infrastructure hamper implementing large-scale citizen-science programs.

Front Ecol Environ 2020; doi:10.1002/fee.2150

Traditional ecological data collection methods are limited 1 in the amount of data that can be gathered across large areas. Such limitations can be reduced by developing citizenscience programs (Devictor et al. 2010; Theobald et al. 2015; Chandler et al. 2017), which involve volunteer participation by members of the public in collecting information following a

\section{In a nutshell:}

- Citizen-science programs are far more common in developed than developing countries

- The lack of volunteer participation is the main reason why there are so few citizen-science programs in developing countries

- A national consortium that includes numerous local coordinators increases volunteer participation

- Collecting bee health data through internet-based questionnaires and face-to-face interviews results in the highest levels of coverage and representativeness

- A large-scale consortium and a combination of several recruitment strategies improves participation and establishment of citizen-science programs in developing countries

\footnotetext{
${ }^{1}$ Universidad Nacional de Río Negro, Instituto de Investigaciones en Recursos Naturales, Agroecología y Desarrollo Rural, San Carlos de Bariloche, Río Negro, Argentina; ${ }^{2}$ Consejo Nacional de Investigaciones Científicas y Técnicas, Instituto de Investigaciones en Recursos Naturales, Agroecología y Desarrollo Rural, San Carlos de Bariloche, Río Negro, Argentina; ${ }^{3}$ Evolution Génome Comportement et Ecologie, CNRS, IRD, Université Paris-Sud, Université Paris-Saclay, Gif-sur-Yvette, Paris, France ${ }^{*}$ (fabrice.requier@egce.cnrs-gif.fr); ${ }^{4}$ Centre for Environmental and Climate Research, Lund University, Lund, Sweden
}

protocol provided, designed, or validated by experts in the field of study (Dickinson et al. 2010). Citizen participation not only assists scientists in collecting large amounts of data over broader spatiotemporal scales, but also connects members of the general public to science, which may potentially increase public awareness of conservation and environmental issues (Van Rijsoort and Jinfeng 2005; McKinley et al. 2017; Ryan et al. 2018). Citizen science may also spur innovation through the exchange of ideas, information, and inspiration (Herrick et al. 2018), and therefore can potentially advance scientific knowledge across a wide range of disciplines (Silvertown 2009; Devictor et al. 2010; Follett and Strezov 2015).

Benefits derived from citizen-science programs often promote human well-being, for instance through education, better management of ecosystems, greater support for stakeholders' activities, and more effective policy making (Conrad and Hilchey 2011; Follett and Strezov 2015). Although developing countries need to improve human livelihoods, they often lack the resources to develop citizen-science programs (Danielsen et al. 2005; Chandler et al. 2017; Pocock et al. 2018), especially in Africa and Latin America (Figure 1a). Indeed, most citizenscience programs have been developed and conducted in countries that have a high human development index (HDI; Figure $1 \mathrm{~b}$ ). For instance, popular voluntary biological surveys (eg breeding bird surveys, Christmas bird counts, butterfly monitoring programs) collect a wealth of data on bird and butterfly populations in the developed countries of Europe and North America (eg Schmeller et al. 2009; Sullivan et al. 2009; Devictor et al. 2010).

One reason for the success of citizen-science programs is their extensive use of internet-based platforms, whereby in-person interviews and other traditional methods of data collection are replaced by self-participation via online question- 

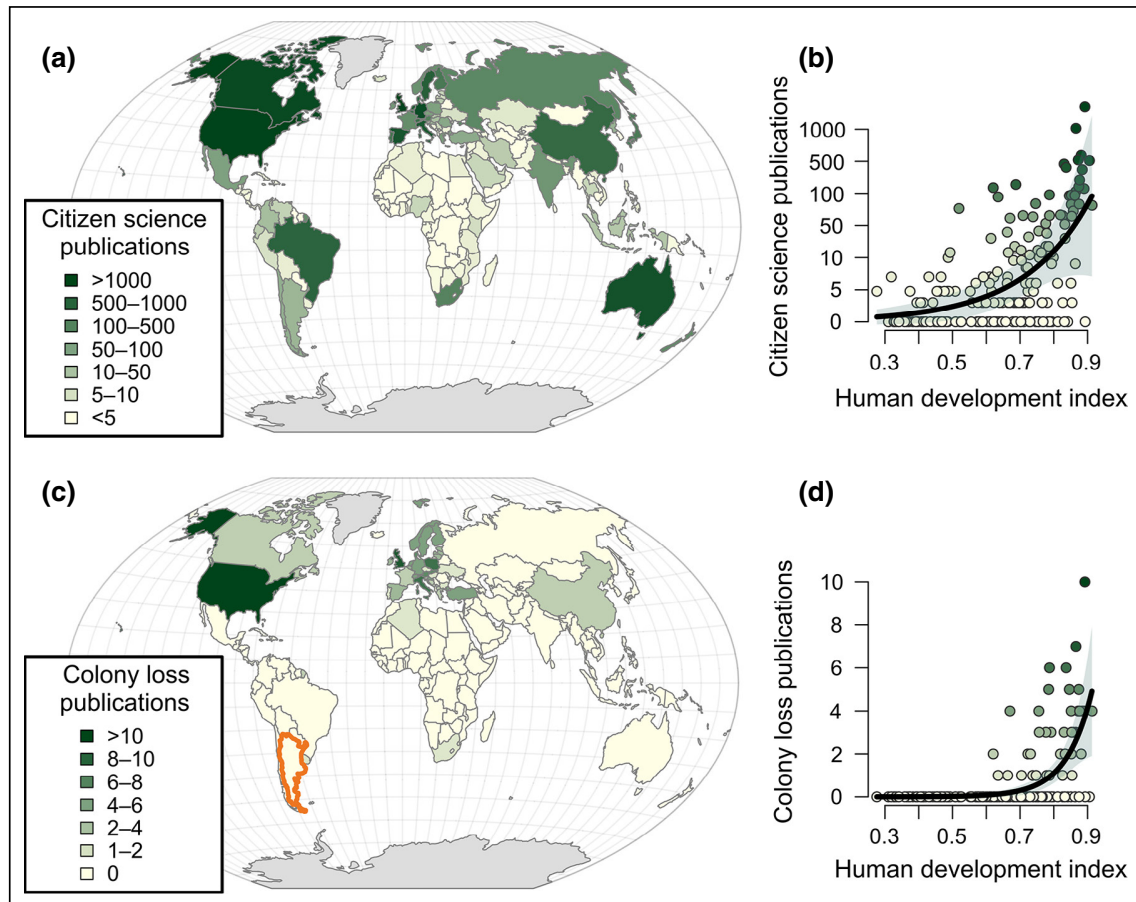

(d)

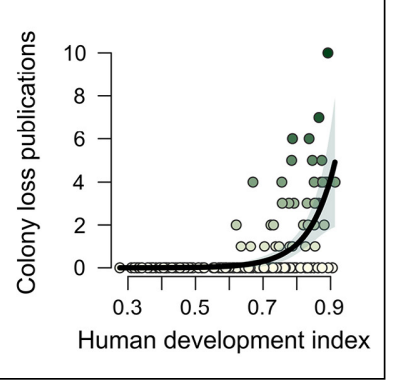

Figure 1. Global map of where citizen-science studies are conducted. (a) The global distribution of citizen-science studies published over the past 30 years (1987-2017); 7774 studies were identified following Follett and Strezov (2015), based on Web of Knowledge searches. (b) The number of citizen-science publications per country was found to be positively associated with its human development index (HDI; HDR 2018). (c) The global distribution of honey bee colony loss publications produced through citizen-science programs. Data were collected through an exhaustive synthesis of 39 papers (complete list in WebPanel 1). The Argentinean study case is shown in orange. (d) The number of colony loss publications per country was also positively influenced by its $\mathrm{HDI}$, and was correlated with the number of citizen-science publications (see WebFigure 1).

naires (Goodchild 2007; Sullivan et al. 2009; Bonney et al. 2014). This approach provides numerous advantages, including increased capacity for public outreach, reduced material costs, and the development of large-scale networks with real-time information-sharing capabilities (Sullivan et al. 2009; Newman et al. 2012; Herrick et al. 2018). Limited internet access in many parts the developing world (Gulati 2008) may therefore at least partially account for why these countries are currently underrepresented in citizen-science programs (Silvertown 2009; Newman et al. 2012; Pocock et al. 2018). It has been suggested that limited networking, organizational, and collaboration capacities are the most common factors that slow the implementation of large-scale citizen-science programs in developing countries (Conrad and Hilchey 2011; Maggi et al. 2016; Pocock et al. 2018). Although these difficulties are recognized (Chandler et al. 2017; Pocock et al. 2018), there is a critical lack of field assessment on how to improve participation and establish citizen-science programs in developing countries.

We used, and assessed the effectiveness of, a participatory method - specially adapted for developing countries - for organizing and connecting local networks of volunteers at large scales. This approach was based on the assumption that volunteers and stakeholders who share a common interest in a spe- cific issue are regionally organized and structured but lack connections between regions. We therefore established a national consortium to facilitate interregional connections, improve the dissemination of standardized questionnaires (Danielsen et al. 2005), and enhance the collection of large-scale datasets. We also assessed whether face-to-face survey interviews could be used to offset limited internet access and to what extent such interviews could influence responses. Some studies suggest that face-toface interviews and online questionnaires could vary in terms of response success, spatiotemporal range, and content of answers (Goodchild 2007; Schmeller et al. 2009).

As a case study, we developed a program to monitor the loss of honey bee (Apis mellifera) colonies, in which beekeepers recorded losses and health issues among the honey bees (vanEngelsdorp et al. 2012). The program was initiated because of concerns about the ecological, agronomic, and social consequences of global honey bee declines (Goulson et al. 2015; Potts et al. 2016). However, as with the global discrepancies in citizen-science programs generally (Figure 1a), bee colony loss monitoring programs have been widely implemented in the Northern Hemisphere (eg Europe and the US; Figure 1c) but are largely absent in developing countries (Figure 1d; WebPanel 1). The lack of nationwide colony loss monitoring programs in these countries prevents assessment of the current status of bee colony collapse disorder. Beekeeping also plays important socioeconomic roles in many developing countries; in Latin America, for example, beekeepers manage $\sim 8$ million honey bee colonies, which produce more than 200 million tons of honey per year (Requier et al. 2018a). The absence of monitoring programs is therefore of great concern throughout Latin America, and especially in Argentina, which has the largest number of beekeepers and the highest levels of honey production and exportation (Requier et al. 2018a). We therefore initiated a monitoring program focusing on honey bee colony losses in Argentina and evaluated whether (1) the establishment of a National Beekeeping Consortium - as a large-scale organization enhanced voluntary participation of beekeepers and (2) whether methodological differences between recruitment strategies (online questionnaires and face-to-face interviews) influenced volunteer profiles or survey results.

\section{Methods}

\section{Citizen-science program in Argentina}

We implemented a citizen-science program to record the rate of honey bee colony loss in Argentina during 2015-2016 
(Figure 1c; Requier et al. 2018b). To estimate summer colony losses, beekeeping management, and bee health in Argentina, we selected questions commonly used in similar monitoring programs, including the Prevention of Honey Bee Colony Losses (COLOSS) questionnaire used to estimate winter colony loss in European countries (van der Zee et al. 2013), and questionnaires used by the Bee Informed Partnership (Kulhanek et al. 2017) and the EPILOBEE consortium (Jacques et al. 2017) - programs that were developed in the US and Europe, respectively (for more details see WebPanel 2). We adapted the questions to account for differences in Northern and Southern Hemisphere seasonal phenology, types of diseases, and botanical origins of honey (in order to make the questionnaire more compatible with South American biogeographic conditions), and prepared a Spanish translation.

\section{National Beekeeping Consortium}

We built a national organization - the National Beekeeping Consortium (NBC) - to represent the interest of beekeepers in Argentina. Because beekeeping activity is distributed heterogeneously across the Argentinian provinces (Figure 2a; RENAPA 2018), we ensured that the composition of the NBC reflected differences in provincial beekeeping activity levels (that is, with more members of the consortium in provinces that contained more beehives) (WebFigure 2). Members of this organization included a coalition of beekeeping coordinators from governmental agencies, beekeeping associations, and research institutes (Figure 2b); these were recruited based on their fieldwork involvement. Each coordinator has his/her own network of 10 to 60 beekeepers, and so the national network included a contact list of 1191 beekeepers. To evaluate the benefits of the NBC, we analyzed whether the number of responses to the bee colony loss survey varied with the number of coordinators across provinces. To do so, we fitted a generalized linear model (GLM) with Poisson error structure ( $\mathrm{glm}$ function in the $\mathrm{R}$ base package; $\mathrm{R}$ Core Team 2017). This model included the recruitment strategy as a categorical predictor (two levels: face-toface interview or online questionnaire), the number of coordinators as a quantitative predictor, and the interaction between the recruitment strategy and the number of coordinators. Because data collection in each province can be affected by both the number of coordinators and the level of beekeeping activity (both correlated; WebFigure 2), we determined which of these two variables was more likely to support improvements in data collection. To disentangle direct versus indirect effects of the consortium and beekeeping activity, we fit GLMs with Poisson error structures to compare their respective contributions to data collection. All possible combinations of one or more variables were evaluated. The Akaike information criterion (AIC) was used to rank the candidate models to identify the best compromise between fit and complexity (WebTable 1). Pearson residuals were extracted and inspected against fitted values (residuals

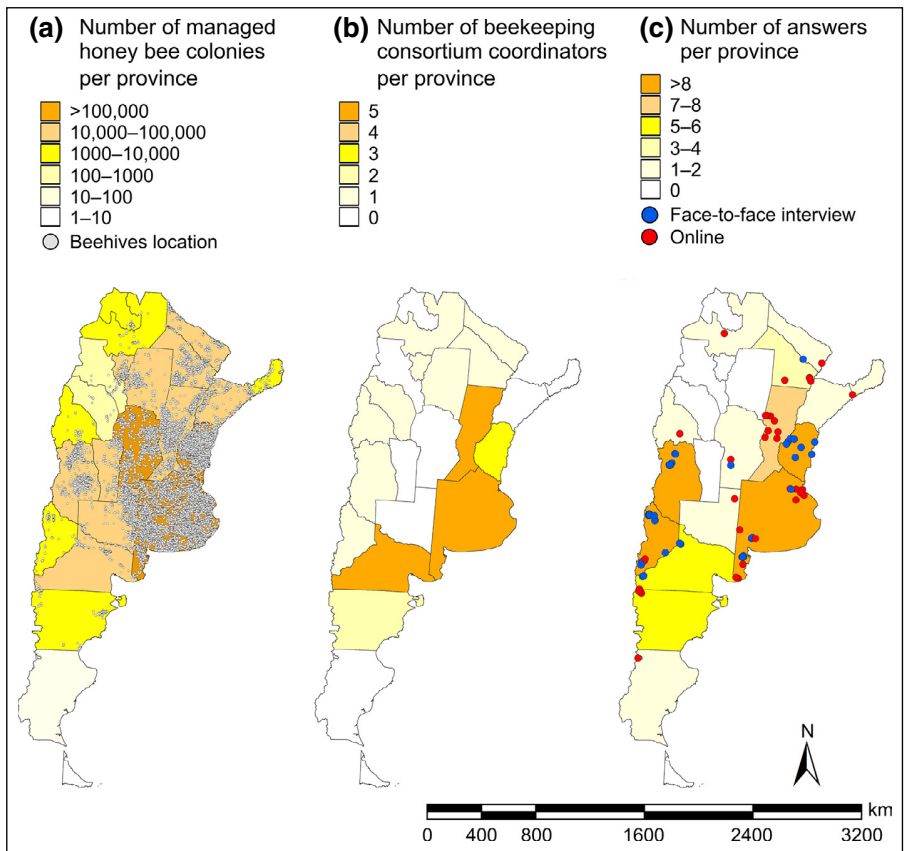

Figure 2. A citizen-science program, implemented in 2015-2016, focusing on honey bee colony losses in Argentina. (a) National distribution of managed honey bee colonies. (b) Number of coordinators associated with the National Beekeeping Consortium in each province. (c) Spatial distribution of beekeepers' participation; traditional face-to-face interviews are shown in blue circles and online questionnaires are shown in red circles.

versus fitted plot and normal quantile-quantile [Q-Q] plot) to assess the suitability of the statistical models.

\section{Participant recruitment strategies}

We implemented two participant recruitment strategies. In the "online strategy", beekeepers were invited to self-report their answers using a web-based questionnaire. This invitation was distributed by email to the beekeepers on the consortium contact list, as well as to beekeeping social networks and national beekeeping journals. In the "face-to-face strategy", we provided a printed version of the questionnaire used in the online strategy to beekeepers in Argentina who did not have internet access or preferred not to respond online, and conducted face-to-face interviews with these individuals. Interviews were performed by consortium coordinators during regular meetings of local beekeeping associations.

To analyze and compare the effects of the two recruitment strategies on data collection, we first calculated the geographical distance between each location of response (distm function in the R geosphere package) as an estimation of the spatial distribution of the responses. We calculated a random accumulating distance function between response locations, for which we ran 10,000 iterations for each recruitment strategy to mitigate the variation in sample size (see Results section). The spatial distribution in responses between the face-to-face and online strategies was compared using GLM with Gaussian error structure. We then modeled the temporal accumulation of responses during the 2 weeks after recruitment for each 
online recruitment strategy (ie email, journal, social network, and website) as a spline function of time using generalized additive models ( $g$ am function in the $\mathrm{R} m g c v$ package).

\section{Methodological effect assessment in answers}

We analyzed the response success rate (ie the proportion of beekeepers answering a question) and the content of the responses to evaluate the potential methodological differences between the two recruitment strategies. The response success rate per question was compared between strategies using generalized linear mixed-effects models (glmer function in the $\mathrm{R}$ lme4 package) with a binomial error structure and the province as a random factor to account for the spatial non-independence of provincial repeated measurements. We used the same modeling approach for analyzing the content of the responses but implemented a Gaussian error structure for quantitative responses and a binomial error structure for binary responses (eg "yes" or "no").

\section{Results}

\section{Consortium effect on data collection}

A total of 104 beekeepers (8.7\% of the beekeepers in our contact list), managing 582 apiaries (4.6\% of the apiaries registered in Argentina) and 22,945 beehives (2.7\% of the beehives registered in Argentina), participated in the monitoring program. The distribution of responses covered 16 of the 23 Argentinian provinces (Figure 2c); provinces without participation contained less than $6 \%$ of the national stock of honey bee colonies. AIC analysis indicated that the amount of data collected per province (ranging from 0-11 responses $\times$ participant recruitment strategies) was better explained by the number of consortium coordinators than by provincial beekeeping activity (relative importance weights were 1.0 and 0.88 , respectively), suggesting that the number of consortium coordinators had a direct effect on improving data collection. The number of responses per province was positively influenced by the number of consortium coordinators per province ( $n=48, Z=0.302$, $P<0.001$; Figure 3a). Interestingly, the significant interaction between the number of consortium coordinators and the participant recruitment strategies $(n=48, Z=$ $0.203, P=0.044$ ) showed a higher ratio in data collection for the online strategy in provinces with more consortium coordinators (Figure 3a).

\section{Participant recruitment strategies}

Data collection was carried out by means of 56 traditional face-to-face interviews and 48 self-reported online submissions. Over the period of data collection (1 Jul 2016 to 1 Dec 2016; that is, after the end of the Argentinean 2015-2016 season of beekeeping; Figure $3 \mathrm{~b}$ ), there were significantly more daily collected responses from the face-to-face strategy (5.6 \pm 7.0 responses per day, mean \pm standard deviation) than for the online strategy $(1.7 \pm 1.1$ responses per day) $(n=48, t=$ 35.28, $P<0.001)$. Among online recruitment strategies, email invitations elicited significantly more responses than face-toface interviews (WebFigure 3). The spatial distribution of responses was compared among the recruitment strategies for the 39 online respondents and the 52 face-to-face respondents who had reported the location of their beehives at least at the municipal scale (of 48 and 56 total respondents, respectively). For the same number of responses (ie $n=39$ ), spatial distribution was greater for the online strategy than the faceto-face strategy ( $n=10,000$ iterations, $t=9335.38, P<0.001$; Figure 3c).

\section{Effect of methodology on responses}

The response rate for the 25 questions on the questionnaire ranged from $18.8 \%$ to $96.4 \%$ (WebFigure 4). Regardless of

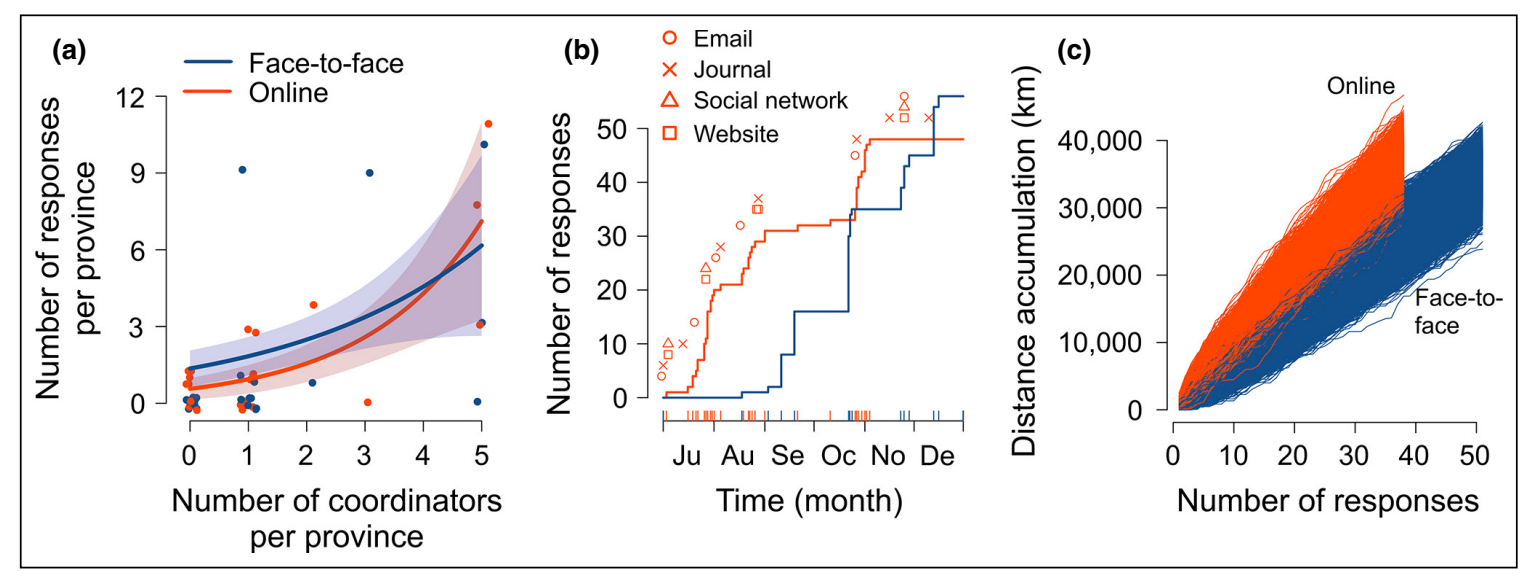

Figure 3. (a) Involvement of more consortium coordinators in a citizen-science project increases the number of responses, regardless of whether traditional face-to-face interviews or online questionnaires are used. The solid line is the prediction of the generalized linear model and the shaded area indicates the 95\% confidence interval. (b) Cumulative time series of responses in traditional face-to-face interviews (in blue) and online questionnaires (in red). Symbols indicate the event timeline for each online recruitment strategy. (c) Spatial distributions of traditional face-to-face interviews and online questionnaire responses, calculated using a random accumulating distance function (see Methods). 
the participant recruitment strategy used, beekeepers were largely unwilling to reveal the location of their beehives (18.8\% and $26.8 \%$ response success for online and faceto-face recruitment strategies, respectively) and the economic details of their activities (62.5\% and 58.9\% response success). Significant differences in response rate between the two recruitment strategies (online versus face-to-face) were observed for nine of the 25 questions, with higher response rates for the face-to-face strategy (WebFigure 4; WebTable 2 ). Moreover, another methodological effect was observed within the survey results for several of the questions, with a trend toward higher values for the online strategy (Figure 4). Although methodological effects were not detected for questions about the age of the beekeeper, the number of colonies, or beekeeping-associated education, suggesting that the responder profiles were similar for the two recruitment strategies (see WebPanel 3), the values for "swarming control", "frequency of visits", and "summer colony losses" were higher for the online approach than for the face-toface approach (Figure 4; WebTable 3). As an example, beekeepers reported $2.9 \% \pm 4.8 \%$ versus $6.5 \% \pm 6.9 \%$ of summer colony losses through face-to-face interviews and through the online questionnaire, respectively.

\section{Discussion}

\section{Consortium matters in data collection}

Although there is a general desire to foster citizen science in developing countries (Pocock et al. 2018) with a view to establishing international and global projects (Chandler et al. 2017), the techniques used to collect data through citizen-science initiatives in developed countries may not work in developing countries (Danielsen et al. 2005; Chandler et al. 2017; Pocock et al. 2018). We have demonstrated that the establishment of the NBC, which included provincial coordinators, was a key contributor to data collection about honey bee colony losses in Argentina. For one, collaboration between the NBC and numerous local beekeeping associations (that is, beekeeping technical coordination within each province through, for example, Asociación Apícola de la Comarca Andina, Sociedad Argentina de Apicultores, Programa Apícola Provincial Pro Miel, and Programa Nacional Apícola [PROAPI]) greatly increased access to survey material distributed via email. In addition, advertising the survey in national beekeeping magazines, in university and research institutes, and in networks of beekeeping associations further increased questionnaire distribution. Finally, conducting direct face-to-face interviews with beekeepers also improved the efficiency of the process.

At the same time, however, the relatively small number of beekeepers who responded to the surveys underscores the challenge of collecting data via citizen-science programs in South America as compared to programs in the US and

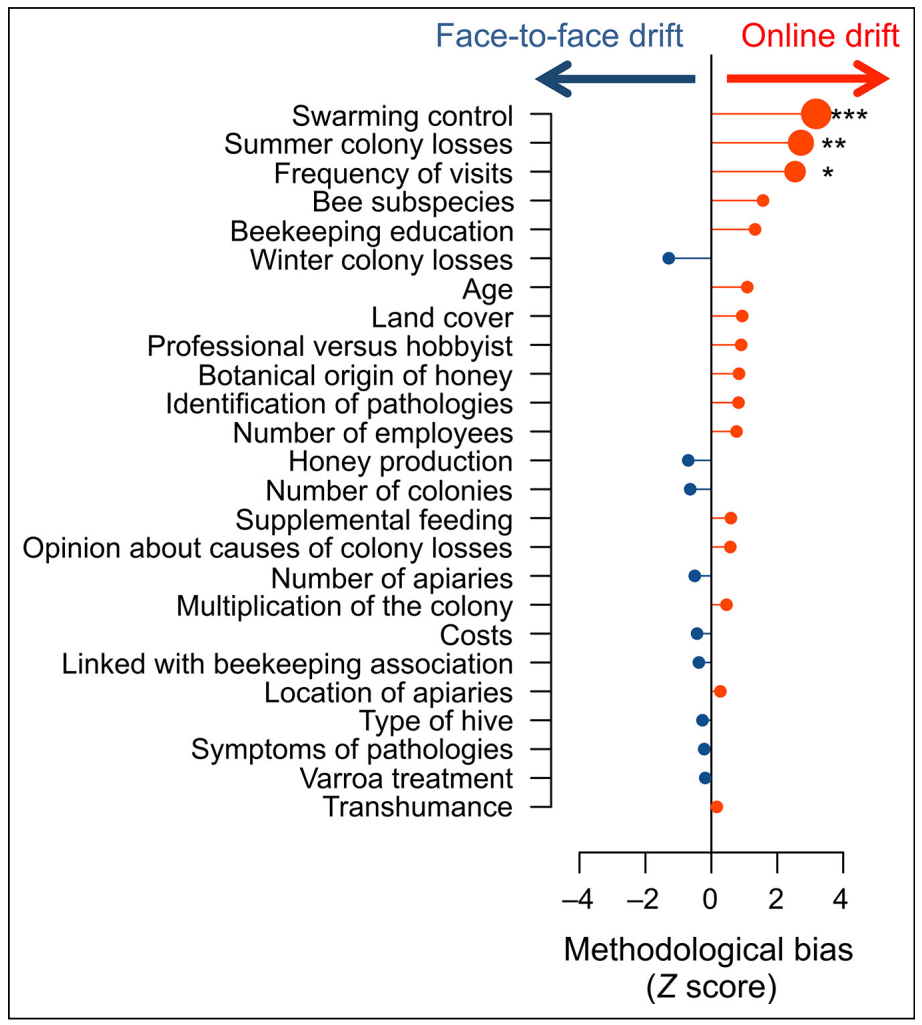

Figure 4. Differences in response values between traditional face-to-face interviews and online questionnaires. Positive values reflect trends in online questionnaires and circle sizes indicate the effect level; asterisks indicate the significance level (see Methods): ${ }^{\star \star \star} P<0.001,{ }^{\star \star} P<0.01$, and ${ }^{\star} P<0.05$.

Europe. Participation by Argentinean beekeepers was only about one-third (in absolute terms) that of participation in similar surveys in Europe and North America in the first year (vanEngelsdorp et al. 2008; Brodschneider et al. 2010; van der Zee et al. 2012). This low participation rate may be due to limited internet access (Gulati 2008) and a lack of organization at larger spatial scales (Conrad and Hilchey 2011; Maggi et al. 2016) or may reflect a lower level of interest among the citizens of developing countries (Pocock et al. 2018), possibly because potential respondents do not perceive any personal benefit from participation (eg no compensation) or due to a lack of personal resources or time to support participation. Additional social-science research is needed to more fully evaluate whether and how these social factors influence participation in developing countries. Given that the volunteers involved in our survey (ie beekeepers) have personal concerns about honey bee health and conservation, we expected the participation rate to be higher than that in citizen-science programs involving noninterested respondents, as Wilson et al. (2017) did in the US, measuring public understanding of bee diversity. However, the level of participation in Argentina was higher than that in several other countries, such as South Africa (Pirk et al. 2014), Uruguay (Antúnez et al. 2017), and China (van der Zee et al. 2012). 


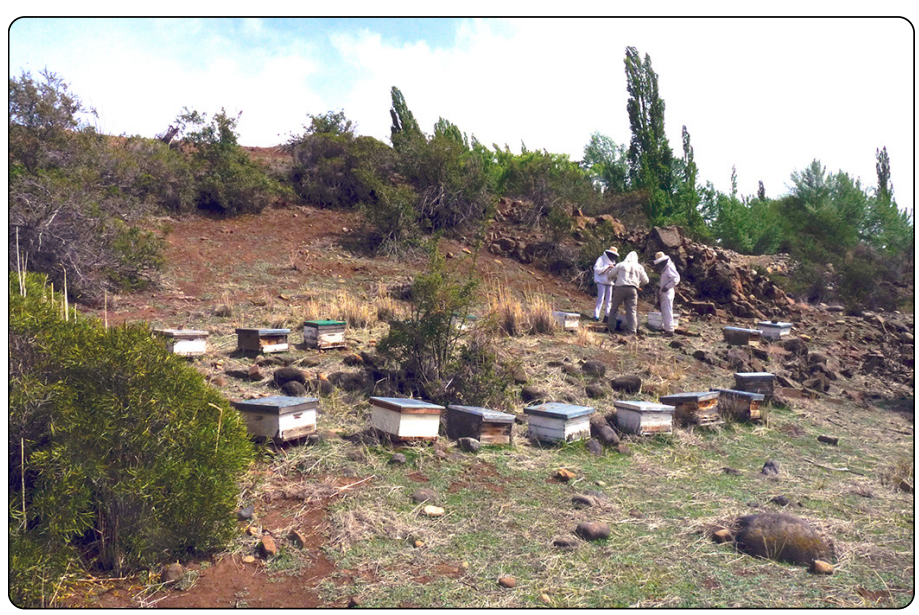

Figure 5. Beekeepers in northern Patagonia (Nahueve, Argentina) are isolated from cities, high-speed internet access, and transportation infrastructure.

The NBC established local networks of volunteer citizen scientists over a large spatial scale, which seems to be a key factor in obtaining sufficiently representative amounts of data. A common feature of successful surveys regarding honey bee colony loss is the implementation of interinstitutional networks of beekeepers and consortiums (eg the Bee Informed Partnership [vanEngelsdorp et al. 2008; Kulhanek et al. 2017] in the US and COLOSS group [van der Zee et al. 2012, 2013; Brodschneider et al. 2016] and the EPILOBEE consortium [Jacques et al. 2017] in Europe). Therefore, investing in large-scale organizations and connections among local networks may promote the establishment of citizen-science programs in Latin America and Africa (Figure 1). The NBC is one example of a successful large-scale organization, but other approaches should also be tested and developed.

\section{Participant recruitment strategies affect honey bee colony loss estimates}

Colony collapse disorder of managed honey bees currently threatens honey production and crop pollination in many countries, which could have negative social, economic, and ecological effects (Potts et al. 2016). As there is a lack of data to identify the causes of this disorder - thought to be driven by the combined stress of parasites, pesticides, and lack of flowers (Goulson et al. 2015; Potts et al. 2016) - large-scale citizen-science programs have been initiated in many countries around the world to monitor honey bee colony losses (Figure 1; WebPanel 1). Data collected by these programs have revealed that up to $25-50 \%$ of honey bee colonies may be lost every winter in Europe (Brodschneider et al. 2016) and North America (Kulhanek et al. 2017). We found that reported estimates of summer honey bee colony losses in Argentina were higher among online questionnaire respondents than among those who participated in traditional face-to-face interviews; however, reports of winter colony losses did not differ between recruitment strategies. Although surveys of the colony losses of a given year occur during the beekeeping season of the subsequent year, beekeepers can be influenced by their personal experiences in voluntarily responding to the survey, suggesting that beekeepers who have been subject to colony losses may be more motivated to respond to colony loss surveys, and may also be more prone to search for such citizen-science programs online. Another explanation for the differences between face-to-face and online responses could be a bias toward people with internet access (Figure 5), which could, for example, explain the differences observed in responses for the two common beekeeping practices, "swarming control" and "frequency of visits".

Citizen-science programs are robust tools for collecting large amounts of data and as such have great potential to advance scientific knowledge, influence policy making, and guide resource management; however, this potential can only be realized if datasets are of high quality (Kosmala et al. 2016). Evidence of methodological effects on estimates of summer colony losses in honey bees calls into question the representativeness of the colony loss estimates presented in previous studies conducted in South Africa (Pirk et al. 2014), Uruguay (Antúnez et al. 2017), and China (van der Zee et al. 2012), where data sources were not identified. Moreover, in most surveys of colony losses, there has been no assessment of the potential effects of the participation recruitment strategies used (eg Brodschneider et al. 2016; Jacques et al. 2017; Kulhanek et al. 2017). Therefore, we recommend that the effects of the data source used in the statistical analyses be rigorously assessed prior to application in future surveys.

\section{Lessons learned and recommendations}

Citizen science can improve data collection for research and consequently can deliver social, economic, and ecological benefits (Conrad and Hilchey 2011; Theobald et al. 2015; Ryan et al. 2018). Our study focused on a large-scale citizenscience program in Argentina; as of now, such studies are a rarity in the Southern Hemisphere (Figure 1). We propose that citizen-science programs in developing countries be implemented via the development of a large-scale consortium to facilitate inter-regional connections between citizen-science participants and to expand their spatial coverage. Such a consortium also facilitates the standardization of questionnaires. Given that face-to-face interviews increase response rates and online questionnaires improve the spatial distribution, we recommend that these two participant recruitment strategies be used in tandem to improve future citizen-science programs. Furthermore, the data source must be included as a predictor variable in statistical analyses to mitigate any methodological effects.

We identified several matches between our results and suggestions from previous studies, including (1) establishing a national 
consortium to support networks and inter-regional exchanges (Conrad et al. 2011; Maggi et al. 2016); (2) coupling web-based surveys with traditional face-to-face interviews in order to mitigate the (common) problem of limited internet access (Pocock et al. 2018) and the potential loss of interest in responding to online surveys due to the ever-expanding amount of information available online and the large number of such requests; (3) performing face-to-face interviews as a means of reinforcing social links among volunteers and professionals/scientists (Van Rijsoort and Jinfeng 2005; Conrad and Hilchey 2011), and for mitigating the substantial distrust in public engagement in policy development that prevails in many developing countries; and (4) standardizing questionnaires for large-scale projects (Danielsen et al. 2005). We argue that these recommendations can serve as a generic framework for improving participation in citizen-science projects in developing countries.

\section{Acknowledgements}

This work was supported by grants from the Agencia Nacional de Promoción Científica y Tecnológica (PICT 2016-0305), Consejo Nacional de Investigaciones Científicas y Técnicas (PDTS Res 298/14), and Universidad Nacional de Río Negro (PI 40-B-567 and PDC 40-B-557). Special thanks to N Garcia and the members of the National Beekeeping Consortium for their help in data collection, and to all the participating volunteer beekeepers. We thank CL Morales, N Pérez-Méndez, and $\mathrm{D}$ vanEngelsdorp for constructive comments on the manuscript. FR and LAG designed the research project; FR collected and analyzed the data; FR wrote the first version of the manuscript; FR, GKSA, FJO, and LAG contributed greatly to the drafts and gave their final approval for publication.

\section{References}

Antúnez K, Invernizzi C, Mendoza Y, et al. 2017. Honey bee colony losses in Uruguay during 2013-2014. Apidologie 48: 364-70.

Bonney R, Shirk JL, Phillips TB, et al. 2014. Next steps for citizen science. Science 343: 1436-37.

Brodschneider R, Moosbeckhofer R, and Crailsheim K. 2010. Surveys as a tool to record winter losses of honey bee colonies: a two year case study in Austria and South Tyrol. J Apicult Res 49: 23-30.

Brodschneider R, Gray A, van der Zee R, et al. 2016. Preliminary analysis of loss rates of honey bee colonies during winter 2015/16 from the COLOSS survey. J Apicult Res 55: 375-78.

Chandler M, See L, Copas K, et al. 2017. Contribution of citizen science towards international biodiversity monitoring. Biol Conserv 213: $280-94$

Conrad CC and Hilchey KG. 2011. A review of citizen science and community-based environmental monitoring: issues and opportunities. Environ Monit Assess 176: 273-91.

Danielsen F, Burgess ND, and Balmford A. 2005. Monitoring matters: examining the potential of locally-based approaches. Biodivers Conserv 14: 2507-42.
Devictor V, Whittaker RJ, and Beltrame C. 2010. Beyond scarcity: citizen science programmes as useful tools for conservation biogeography. Divers Distrib 16: 354-62.

Dickinson JL, Zuckerberg B, and Bonter DN. 2010. Citizen science as an ecological research tool: challenges and benefits. Annu Rev Ecol Evol S 41: 149-72.

Follett R and Strezov V. 2015. An analysis of citizen science based research: usage and publication patterns. PLoS ONE 10: e0143687.

Goodchild MF. 2007. Citizens as sensors: the world of volunteered geography. GeoJournal 69: 211-21.

Goulson D, Nicholls E, Botías C, and Rotheray EL. 2015. Bee declines driven by combined stress from parasites, pesticides, and lack of flowers. Science 347: 1255957.

Gulati S. 2008. Technology-enhanced learning in developing nations: a review. Int Rev Res Open Dis 9: 1-16.

HDR (Human Development Reports). 2018. Human development index (HDI) of the UN Development Programme. New York, NY: UN Development Programme.

Herrick JE, Cox DW, Lundgren B, and Nindi S. 2018. Global citizen science for people. Front Ecol Environ 16: 491.

Jacques A, Laurent M, EPILOBEE Consortium, et al. 2017. A panEuropean epidemiological study reveals honey bee colony survival depends on beekeeper education and disease control. PLoS ONE 12: $\mathrm{e} 0172591$.

Kosmala M, Wiggins A, Swanson A, and Simmons B. 2016. Assessing data quality in citizen science. Front Ecol Environ 14: 551-60.

Kulhanek K, Steinhauer N, Rennich K, et al. 2017. A national survey of managed honey bee 2015-2016 annual colony losses in the USA. J Apicult Res 56: 328-40.

McKinley DC, Miller-Rushing AJ, Ballard HL, et al. 2017. Citizen science can improve conservation science, natural resource management, and environmental protection. Biol Conserv 208: 15-28.

Maggi M, Antúnez K, Invernizzi C, et al. 2016. Honey bee health in South America. Apidologie 47: 835-54.

Newman G, Wiggins A, Crall A, et al. 2012. The future of citizen science: emerging technologies and shifting paradigms. Front Ecol Environ 10: 298-304.

Pirk CWW, Human H, Crewe RM, and vanEngelsdorp D. 2014. A survey of managed honey bee colony losses in the Republic of South Africa - 2009 to 2011. J Apicult Res 53: 35-42.

Pocock MJO, Roy HE, August T, et al. 2018. Developing the global potential of citizen science: assessing opportunities that benefit people, society and the environment in East Africa. J Appl Ecol 56: 274-81.

Potts SG, Imperatriz-Fonseca V, Ngo HT, et al. 2016. Safeguarding pollinators and their values to human well-being. Nature 540: 220-29.

R Core Team. 2017. R: a language and environment for statistical computing, v3.3.3. Vienna, Austria: R Foundation for Statistical Computing.

RENAPA (Registro Nacional de Productores Apícolas). 2018. Production database from the National Registry of Beekeeping Producers in Argentina. Buenos Aires, Argentina: Ministerio de Producción y Trabajo.

Requier F, Antúnez K, Morales CL, et al. 2018a. Trends in beekeeping and honey bee colony losses in Latin America. J Apicult Res 57: 657-62.

Requier F, Andersson GKS, Oddi F, and Garibaldi LA. 2018b. Perspectives from the survey of honey bee colony losses 2015-16 in Argentina. Bee World 5: 9-12. 
Ryan SF, Adamson NL, Aktipis A, et al. 2018. The role of citizen science in addressing grand challenges in food and agriculture research. P Roy Soc B-Biol Sci 285: 20181977.

Schmeller DS, Henry PY, Julliard R, et al. 2009. Advantages of volunteer-based biodiversity monitoring in Europe. Conserv Biol 23: 307-16.

Silvertown J. 2009. A new dawn for citizen science. Trends Ecol Evol 24: $467-71$.

Sullivan BL, Wood CL, Iliff MI, et al. 2009. eBird: a citizen-based bird observation network in the biological sciences. Biol Conserv 142: 2282-92.

Theobald EJ, Ettinger AK, Burgess HK, et al. 2015. Global change and local solutions: tapping the unrealized potential of citizen science for biodiversity research. Biol Conserv 181: 236-44.

van der Zee R, Pisa P, Andonov S, et al. 2012. Managed honey bee colony losses in Canada, China, Europe, Israel and Turkey, for the winters of 2008-9 and 2009-10. J Apicult Res 51: 100-14.

van der Zee R, Gray A, Holzmann C, et al. 2013. Standard survey methods for estimating colony losses and explanatory risk factors in Apis mellifera. J Apicult Res 52: 1-36.
vanEngelsdorp D, Hayes J, Underwood RM, and Pettis J. 2008. A survey of honey bee colony losses in the US, fall 2007 to spring 2008. PLoS ONE 3: e4071.

vanEngelsdorp D, Tarpy DR, Baylis K, et al. 2012. The Bee Informed Partnership: using beekeeper's real-world experience to solve beekeepers' real-world problems. American Entomologist 58: 116-18.

Van Rijsoort J and Jinfeng Z. 2005. Participatory resource monitoring as a means for promoting social change in Yunnan, China. Biodivers Conserv 14: 2543-73.

Wilson JS, Forister ML, and Messinger Carril O. 2017. Interest exceeds understanding in public support of bee conservation. Front Ecol Environ 15: 460-66.

\section{Supporting Information}

Additional, web-only material may be found in the online version of this article at http://onlinelibrary.wiley.com/doi/10. 1002/fee.2150/suppinfo 